DOI: 10.20472/IAC.2019.045.029

\author{
SANDRA OBIORA \\ UNIVERSITY OF ELECTRONIC SCIENCE AND TECHNOLOGY OF CHINA, China \\ YONG ZENG \\ UNIVERSITY OF ELECTRONIC SCIENCE AND TECHNOLOGY, China
}

\title{
FACTORS AFFECTING THE ADOPTION OF ALTERNATIVE FINANCING METHODS FOR STARTUPS BY AFRICANS IN CHINA
}

\begin{abstract}
:
Alternative financing methods such as Crowdfunding, and Peer-to-Peer lending in the past few decades are becoming more sort after means of business start-up financing. On the other hand, traditional financing methods such as bank loans are now more difficult to acquire especially across African countries. Taking a sample of 410 Africans in China, this study examines the factors that affect the adoption of alternative financing methods for business start-ups. The results show that internet usage in Africa and China, length of residence in China, and the capital intensity of the type of the business to be started are all significant factors to the preference and adoption of alternative financing methods by Africans residing in China. Seeing as research into Africa's adoption of alternative financing is lacking, this study, this study provides insight where Africans are concerned.
\end{abstract}

\section{Keywords:}

Alternative financing methods, Traditional financing methods, Business Start-ups

JEL Classification: A12, G29, C15 


\section{Introduction and Literature review}

In today's competitive market, traditional financing methods such as bank loans have become progressively difficult to attain. For Africans, it seems that the probability of getting loans is somewhat slimmer with just $5.4 \%$ being the share for loans across African banks compared to the $13.05 \%$ in other non-African developing countries. In the face of this dilemma, Africans looking to start their own businesses are forced to look for alternative means to financing their business. Majority of Business starters often look through other traditional financing methods such as using personal finances, or borrowing from friends and families. [1] This is due to the fact that few people know about the details of alternative financing methods such as Peer-to-peer lending, crowdfunding, and online market places among other forms. As a result they are unable to maximize the options available to them besides traditional methods [2], [3].

Business practice over the years have brought about a series of financing methods, majority of which are in use today in several advanced forms. Business startup financing mainly involves the use of personal savings, borrowing from family and friends, or getting bank loans among these traditional methods, small businesses and entrepreneurs predominantly resort to bank loans as a major source of business financing. As a result, traditional financing methods is 72 times larger by net worth compared to other financing methods [2], [4]. Akorsu et al. (2012) identifed the standard issues which limit the ability for busienss loan seeks from getting the capital they require from banks. As banks are employing the 'cookie cutter' approach to deciding who to lend to, borrowers are faced with higher chances of rejection if their financial details and spreadsheets or credit histories do not add up. In fact, most banks do not consider any other aspects such as a borrower's character besides the hard figures.[6]

Today more than ever, the quick rise in alternative financing methods is undeniable. Businesses are now leaning more towards other sources beyond traditional methods such as bank loans. Among these, Crowdfunding and Peer-to-Peer lending are most prominent [7]-[9]. Much research has been done on the struggle that businesses accorss Sub-Saharan Africa face[5], [10], [11]. Besides Africa, Yiu Su et al posit that bank loan lending failure is just as serious an issue in in Asia. Nevertheless, alternative fincnaing methods like underground financing and venture capitalism are on the rise [12].

Now more than ever, it is quite visible that China's economy is growing rapidly due partly to its successful SMEs (Small and Medium Enterprises). It is also clear that China despite being a developing country, bears many differences to African countries. Rising up to be the second largest economy in the world has enhanced its technological, and economic advancement levels [13]. In fact, the resource availability difference gap is wider than ever between China and most African countries [7]. The SME growth level of China including its population of almost 1.4 billion surpasses that of Africa at 1.2 billion combined. Nevertheless, in both regions, what SMEs take their place as economical backbones [14]. In China's case, SMEs count as the despite the limited accessibility to credit or bank loans SMEs remain a backbone. As a result, Chinese are known to embrace alternative financing sources when compared to other nations [15]. Some methods practiced in China are known as 'underground financiers', or shadow banks, which bear their own risks [16].

In the case of Africa, Sub-Saharan Africa has been analyzed in details as regards financing and are known to experience difficulty with having access to small business startup financing [1], [10]. Most Sub-Saharan African countries face the most 
reluctance from banks when in search of loans. When they are given funding, it is usually on a short term basis and with high interest rates [5] [17].

Several factors can be expected to act as determinants for the preference of alternative financing methods among Africans residing in China. Factors such as their internet activity rates in Africa and in China, or level of online trust, their length of residence in China, their knowledge of alternative financing methods, and certainly the type of business they wish to start are key factors to be considered.

One key variable for this study is their length of residence in China. When living in a new environment, adaptation is a requirement. When people migrate for one reason or another to a different environment than they are used to, be it to study or work, there is a need to adapt to the new culture, lifestyle, and ways of doing things there According to Berry et all, the process of social learning takes place over the course of time [18], [19].

Another key variable considered is the internet activity and online trust level of the respondent while they were in Africa compared to while they reside in China. Seeing as alternative financing methods are majorly online by nature, and require internet infrastructure availability, this variable is innegligible. Currently, internet infrastructure across Africa I still at a developmental stage despite the fact that interent growth on the continent can be linked to economic growth [20]. Internet usage across China on the contrary has grown over the last decade [21]. Following this reasoning, we first hypothesize the following.

Hypotheses 1A: There exists significant effects of residence length, internet usage, and online trust on the respondent's preference for alternative financing methods.

Capital intensity has been known to be a deterrent to many startup attempts.[22] Technology related startups tend to be capital intensive. This is evidential in IT startups who tend to gain capital more from alternative financing sources such as venture capitalist instead of banks [23]-[25], Manufacturing and hybrid style Startups more likely to be rejected but who have higher capital requirements at startup also shows reliance on alternative sources of financing [26]. As such, identifying the relationship between the business type the respondent aims to start and their preference is paramount. With this reasoning, we hypothesize the following.

Hypotheses 1B: There exists significant effects on higher technological intensive startups and the respondent's preference for alternative financing methods.

\section{Research Design and Method}

\subsection{Data Collection and Online Survey.}

The data was collected through the means of an online administered survey. This was sent to Africans residing in China using a snowball sampling method. To ensure that all respondents were indeed Africans residing in China, the survey was started with an information page that allows anyone that doesn't fit into the description to exit the survey. Also, answer options for questions were limited. For example, when we ask the respondents the part of Africa they are from, the options are limited, to being from the north, south, central, east, or west. 'other' is added as an extra option wherein nonAfricans could put in their nationality. Also, we asked for their place of residence in China with 'other' option included to ascertain those who were not residing in China. 
All responses not fitting into the constraints were removed from the analysis. This study also made use of communication means such as Wechat and $Q Q$ which are popularly used within China by Chinese and foreigners residing in China alike.

Clear explanations and definitions of important terminology were provided at the very beginning and throughout the survey. Terms such as alternative, and traditional financing methods were shortly defined in brackets each time they appeared.

Respondents could not use the same device to respond to the survey more than once. Finally, in order to motivate the respondents, red packet lottery games were done via Wechat for those who had successfully completed the survey. The survey was put into two forms. One for computer viewing, and the other for mobile phone viewing.

The survey began with questions on demographics. These included age, gender, educational level, region in Africa, as well as their place and length of residence in China. Afterwards, the study inquired about the respondent's business ownership status, the type and structure of business started. For instance, we wanted to know if the respondents planned to start a merchandising, technology, or service business. We questioned them on whether they wished to start it as a partnership, or sole proprietorship. From this point, questions on their internet activity/ usage rate for online transactions while in Africa and in China were asked. Their level of online trust, knowledge of alternative financing methods, their preference for or against alternative financing methods, past usage rate and experience with it, alongside willingness to use alternative financing methods were asked. Finally, open questions were asked on to get their opinions about alternative and traditional financing methods.

\subsection{Sample}

410 responses were received from the online survey sent out. $26.2 \%$ were female, while $73.8 \%$ were male. A majority at $80 \%$ of respondents were from West Africa, with $10.6 \%$ coming from East Africa. $51.9 \%$ of respondents knew about alternative financing methods while $48.1 \%$ did not know about it. In China, their internet activity was $67.5 \%$ daily while being just $7.7 \%$ back in Africa. $72.1 \%$ of the respondents have resided in China between 1 and 3 years. $82.7 \%$ of the respondents prefer to use traditional financing methods instead of alternative. Only $6.7 \%$ of respondents have used alternative financing methods before, while $62 \%$ of respondents are willing to try out alternative financing methods. Interestingly, up to $54.6 \%$ of respondents considered traditional financing methods reliable, while $69 \%$ considered alternative financing methods to be unreliable.

\subsection{Estimation Approach}

Detailed discussions and analyses will be done on the response frequencies However, to analyze the relationship between the factors, Probit regression is used to ascertain preference for alternative financing methods based on residence length, internet activity, residence length, and business type.

We assume the following regression formulas

$$
\begin{aligned}
& \text { In }\left[\frac{p}{1-p}\right]=\beta_{0}+\beta_{1} \mathrm{RL}+\beta_{2} \mathrm{BT}+\beta_{3} \mathrm{IAC}+\beta_{4} \mathrm{IAA}+\varepsilon \\
& \operatorname{In}\left[\frac{p}{1-p}\right]=\beta_{0}+\beta_{1} \mathrm{RL}+\beta_{2} \mathrm{BT}+\beta_{3} \mathrm{IAC}+\beta_{4} \mathrm{IAA}+\beta_{5} \mathrm{OT}+\varepsilon
\end{aligned}
$$


where $\frac{p}{1-p}$ represents the probability of preferring alternative financing divided by the probability of preferring traditional financing, $R L, B T, I A C, I A A$, and OT are factors about residence length in China, Business type, internet activity in China, internet activity in Africa, and Online trust respectively.

\section{Empirical Results}

To get the first look into the factors that affect preference for alternative financing methods among Africans residing in China, we first check the ratio of preference for alternative financing methods according to each independent variable in details. We consider the sum and mean for each response sorted in terms of preference for alternative financing methods as is shown in the table below.

Table 1: Descriptive Statistics of Key Variables

\begin{tabular}{|c|c|c|c|c|}
\hline & $\begin{array}{l}\text { Total } \\
\text { Observations }\end{array}$ & $\begin{array}{l}\text { Alternative } \\
\text { Financing } \\
\text { Preferred }\end{array}$ & $\begin{array}{l}\text { Traditional } \\
\text { Financing } \\
\text { Preferred }\end{array}$ & $\begin{array}{l}\text { Alternative } \\
\text { Finance } \\
\text { Preference } \\
\text { Ratio }\end{array}$ \\
\hline \multicolumn{5}{|c|}{$\begin{array}{l}\text { Panel A: Residence } \\
\text { length }\end{array}$} \\
\hline$<=6$ months & 40 & 6 & 34 & 0.150 \\
\hline 6 months to $1 \mathrm{yr}$ & 18 & 6 & 12 & 0.333 \\
\hline $1-3 \mathrm{yrs}$ & 297 & 39 & 258 & 0.131 \\
\hline $4-6$ yrs & 36 & 11 & 25 & 0.306 \\
\hline $6-10 \mathrm{yrs}$ & 12 & 4 & 8 & 0.333 \\
\hline$>10 y r s$ & 7 & 3 & 4 & 0.429 \\
\hline \multicolumn{5}{|c|}{ Panel B: Online Trust } \\
\hline Strongly distrust & 22 & 3 & 19 & 0.136 \\
\hline Distrust & 38 & 12 & 26 & 0.316 \\
\hline Indifferent & 254 & 23 & 231 & 0.091 \\
\hline Trust & 67 & 20 & 47 & 0.299 \\
\hline Strongly Trust & 29 & 11 & 18 & 0.379 \\
\hline \multicolumn{5}{|c|}{ Panel C: Internet Activity in China } \\
\hline Monthly and more & 60 & 6 & 54 & 0.100 \\
\hline Weekly & 73 & 12 & 42 & 0.219 \\
\hline Daily & 277 & 35 & 86 & 0.126 \\
\hline \multicolumn{5}{|c|}{ Panel D: Internet Activity in Africa } \\
\hline Monthly and more & 362 & 49 & 313 & 0.135 \\
\hline Weekly & 19 & 5 & 14 & 0.263 \\
\hline Daily & 29 & 11 & 8 & 0.579 \\
\hline
\end{tabular}

From table 1, we observe in panel A that there is an upward trend in terms of preference and resident length in China. The longer the resident length, the higher the alternative financing preference rate. We see a somewhat similar pattern in terms of online trust. In panel $\mathrm{B}$, the more the trust level, the higher the preference rate. For 
online activity in panels $C$ and $D$, we see in the case of internet activity in China, that there seems to be a negative trend between the frequency of internet usage and preference for alternative financing methods. However, in panel $D$, we see a rising positive trend between internet usage frequency and preference for alternative financing methods.

\subsection{Univariate regression of financing preference on the key factors}

In order to prove hypotheses 1 right or wrong, we run a univariate logit regression model testing RL, IAA, IAC, and BT which represent Residence length in China, Internet activity in Africa, Internet activity in China, and Business Type to be started. As business type is a categorical variable, we divide it into BT-MD, BT-MF, BT-IT, BT$\mathrm{HB}$, and BT-Oth which refer to the following business types; Merchandising, Manufacturing, Information Technology and Communication, as well as Others respectively.

Table 2: Logit regression results for the Hypotheses 1 and 2

\begin{tabular}{|c|c|c|c|c|c|c|}
\hline Preference & Coef. & Std. Err. & $z$ & $P>Z$ & $\begin{array}{l}{[95 \%} \\
\text { Conf. }\end{array}$ & Interval] \\
\hline $\mathrm{RL}$ & 0.327 & 0.153 & 2.15 & 0.032 & 0.028 & 0.626 \\
\hline IAA & 0.319 & 0.082 & 3.89 & 0.000 & 0.158 & 0.479 \\
\hline IAC & -0.294 & 0.138 & -2.14 & 0.032 & -0.564 & -0.024 \\
\hline BT-MD & 0.212 & 0.521 & 0.41 & 0.684 & -0.809 & 1.232 \\
\hline BT-MF & 1.732 & 0.688 & 2.52 & 0.012 & 0.383 & 3.081 \\
\hline BT-ITC & 2.130 & 0.568 & 3.75 & 0.000 & 1.015 & 3.245 \\
\hline BT-HB & 1.652 & 0.579 & 2.85 & 0.004 & 0.517 & 2.787 \\
\hline BT-Oth & 0.859 & 0.957 & 0.90 & 0.369 & -1.017 & 2.737 \\
\hline Constant & -2.567 & 0.949 & -3.04 & 0.002 & -4.427 & -0.706 \\
\hline
\end{tabular}

In table 2 we observe that Residence length has a positively significant correlation to preference for alternative financing methods at a $3 \%$ level. In essence, the longer the residence length in China, the higher the preference for alternative financing methods by Africans in China. For Internet activity in Africa, we observe a highly positive and significant relationship between internet activity frequency and preference for alternative financing methods at a $0.0 \%$ level. It indicates therefore that the higher the frequency of a respondent's internet usage while in Africa, the higher their potential of preferring to use alternative financing methods for business startup. On the contrary we find a negative correlation between higher internet activity in China and preference for alternative financing methods at a $3 \%$ significance level. An explanation to this phenomenon upon further research was that in China, activities such as purchasing products, or phone and popular communication tools such as WeChat, or $Q Q$ require internet availability. Therefore, we realized that higher internet activity in China compared to Africa is not an indication of higher preference for alternative financing methods due to the fact that internet activity in China is mostly a day to day necessity, and is therefore not primarily used as a learning tool by the Africans in China.

When we consider Business type as a categorical independent variable, we notice that as a whole business type is significantly positively correlated with preference. However, when we look in details we find that not all categories of business type are 
positively significantly correlated. We note that only those who intend to open Manufacturing, Information Technology, or Hybrid (mix of types) styles of business show this strongly positive significant relationship with preference. Overall, we see that opening an IT and Hybrid show the higher positive level of significance at a $0 \%$ level.

Seeing as majority of the alternative financing methods available for exploitation are online based platforms, we find Online trust to be a relevant factor where alternative financing methods are concerned. As such, we run a more detailed and stringent multivariate regression analysis using the former variables but now including online trust $(\mathrm{OL})$ in terms of parentheses ${ }^{* *},{ }^{* *},{ }^{*}$ which indicate significance levels at $1 \%$, $5 \%$, and $10 \%$ respectively. This is represented in table 3 .

Table 3: Logit regression results for the Hypotheses 1 and 2

\begin{tabular}{|c|c|c|c|c|c|c|}
\hline Independent & \multicolumn{6}{|c|}{ Preference } \\
\hline$R L$ & $\begin{array}{l}0.283^{*} \\
(1.901)\end{array}$ & & & & & $\begin{array}{l}0.302^{* *} \\
(1.974)\end{array}$ \\
\hline IAC & & $\begin{array}{l}-0.396^{\star \star *} \\
(-3.356)\end{array}$ & & & & $\begin{array}{l}-0.331^{* *} \\
(-2.354)\end{array}$ \\
\hline IAA & & & $\begin{array}{l}0.434^{* * *} \\
(5.982)\end{array}$ & & & $\begin{array}{l}0.318^{* * *} \\
(3.871)\end{array}$ \\
\hline OT & & & & $\begin{array}{l}0.400^{\star *} \\
(2.552)\end{array}$ & & $\begin{array}{l}0.287^{*} \\
(1.742)\end{array}$ \\
\hline BT & & & & & $\begin{array}{l}0.000 \\
(.)\end{array}$ & $\begin{array}{l}0.000 \\
(.)\end{array}$ \\
\hline BT-MD & & & & & $\begin{array}{l}-0.315 \\
(-0.644)\end{array}$ & $\begin{array}{l}0.324 \\
(0.613)\end{array}$ \\
\hline BT-MF & & & & & $\begin{array}{l}1.648^{\star \star \star} \\
(2.540)\end{array}$ & $\begin{array}{l}1.926^{* * *} \\
(2.764)\end{array}$ \\
\hline BT-ITC & & & & & $\begin{array}{l}2100^{* * *} \\
(3.884)\end{array}$ & $\begin{array}{l}2.115^{* \star} \\
(3.704)\end{array}$ \\
\hline BT-HB & & & & & $\begin{array}{l}1.743^{* \star *} \\
(3.139)\end{array}$ & $\begin{array}{l}0.694^{* * \star} \\
(2.915)\end{array}$ \\
\hline BT-Oth & & & & & $\begin{array}{l}0.847 \\
(0.930)\end{array}$ & $\begin{array}{l}0.916 \\
(0.951)\end{array}$ \\
\hline Constant & $\begin{array}{l}-2.456^{\star \star \star} \\
(4.605)\end{array}$ & $\begin{array}{l}0.516 \\
(-0.256)\end{array}$ & $\begin{array}{l}-2.639^{* * *} \\
(-6.307)\end{array}$ & $\begin{array}{l}-2.879^{\star \star \star} \\
(-5.398)\end{array}$ & $\begin{array}{l}-2.100^{* * *} \\
(-4.855)\end{array}$ & $\begin{array}{l}-3.291^{* \star \star} \\
(-3.161)\end{array}$ \\
\hline $\mathrm{N}$ & 410 & 410 & 410 & 410 & 410 & 410 \\
\hline
\end{tabular}

Note: The $t$-statistics are reported in parentheses. ${ }^{* \star *},{ }^{* *}$, and ${ }^{*}$ indicate significance at the levels of $1 \%, 5 \%$ and $10 \%$, respectively.

Table 3 shows similar results as table 2 . However, in this case we only consider the significance levels of these variables with the dependent variable preference in this multivariate regression. What we find here is that similarly, Residence length remains positively significant but this time at a $10 \%$ level unlike before where it was significant at a 3\% level. Similarly, we see that internet activity in Africa remains highly significant at a $1 \%$ level, and internet activity at a negative $1 \%$ level. We see that in terms of business type, Manufacturing, IT, and Hybrid businesses show the highest levels of significance all at the $1 \%$ level. When Online trust is introduced into this regression, we find that online trust is positively significant with preference at a $5 \%$ level. In essence, the higher the online trust, the higher the preference of alternative financing 
methods. Once more the above regression table shows that internet activity in Africa, residence length, business type, and now online trust are important factors that determine preference and adaptation to alternative financing methods.

\subsection{Results and discussion}

Before the analyses, we hypothesized two things. First that there exist significant effects of residence length, internet usage, and online trust on the respondent's preference for alternative financing methods, and second; that there exists significant effects on higher technology intensive startups and the respondent's preference for alternative financing methods. Upon running the two multivariate regression formulas above, we find that hypotheses 1 and 2 are proven in tables 2 and 3 . We find that indeed, residence length, internet usage in Africa, as well as online trust have significantly positive relationships with preference for alternative financing methods. However, for hypothesis 1 we find that internet Activity in Africa has a significantly negative relationship with preference.

For hypotheses 2, we find that indeed, the more a business type is technology intensive at startup the higher the preference for alternative financing methods by Africans in China. We can therefore say that hypotheses 1 and 2 are fundamentally proven right, and our robustness tests lets us accept these results as truly significant.

When we look at the raw data and statistics, it appears that that traditional financing methods is more preferred overall by the Africans residing in China.

\subsection{Robustness test}

We ran the Jaque-Bera skewness-kurtosis test on all raw data in order to see that the regression models run were plausibly normally distributed. As this test looks into the properties of skewness in the raw data and also takes into account chi squared at 2 degrees of freedom, it is a suitable test for this study. After running it, we found that the joint analyses of adjusted chi squared and the $P$ value of Chi squared produces a highly significant result with a P-value of 0.000 for all 410 observations. As our $p$-value is highly significant at $0.00 \%$, we can conclude that we have enough evidence in this study with which to reject all null hypotheses of normality. Therefore, the relationships between variables found are in fact significantly relevant.

\section{Conclusion and Recommendations}

As traditional financing methods such as bank loan attainment have become more difficult to attain especially for Africans, now more than ever alternative financing methods offer hopeful options. Alternative financing methods such as Peer to peer lending, Crowdfunding, and other online markets connect lenders to borrowers, and serve as a tool for startup financing. However, several key factors play a role in the adoption of alternative financing methods by Africans. In this study, we find that for Africans in China, several key factors affect their preference for alternative financing methods. We find that internet usage of the respondents while in Africa plays a role. We see a positive significant effect between higher internet usage while in Africa and preference for alternative financing methods while in China. We also find that higher online trust alongside longer residence length in China have significant positive effects 
on preference for alternative financing methods. Interestingly, preference is affected by the type of business to be started. Information Technology, and Manufacturing startups had highly positive significant effects with preference for alternative financing methods.

Identifying the preference of Africans, especially those in diaspora is a key element to deciphering the factors affecting the poor state of alternative financing methods adoption. Future research can perhaps look at the state and usage rate of alternative financing methods in Africa, as well as the determinants to preference and the rate of adoption of alternative financing methods by Africans in Africa, and Africans across the globe.

\section{References}

[1] C. R. Beck Thorsten, "SME Finance in Africa," J. Afr. Econ., vol. 23, no. 5, pp. 583-613, 2014.

[2] K. G. Mills, "The State of Small Business Lending: Credit Access during the Recovery and How Technology May Change the Game," Harv. Bus. Rev., no. 15-004, pp. 1-31, 2014.

[3] S. C. and T. C. Obiora, "The Case of Alternative Versus Traditional Financing: A Literature Review," Arch. Bus. Res., vol. 5, no. 9, pp. 42-53, 2017.

[4] OECD, "Financing SMEs and entrepreneurs 2015 - An OECD Scoreboard," 2015.

[5] P. K. Akorsu, D. Agyapong, and C. Author, "Alternative Model For Financing SMEs in Ghana," Int. J. Arts Commer., vol. 1, no. 5, pp. 136-148, 2012.

[6] R. A. Cole, L. G. Goldberg, and L. J. White, "Cookie Cutter vs. Character: The Micro Structure of Small Business Lending by Large and Small Banks," J. Financ. Quant. Anal., vol. 39, no. 02, p. 227, 2004.

[7] L. Neville, "Alternative Financing," Global Finance, pp. 22-26, 2012.

[8] M. Lin, "Peer-to-Peer Lending : An Empirical Study," in 15th Americas Conference on Information Systems, 2009, p. 8.

[9] M. Segal, "What Is Alternative Finance?," Off. Advocacy, vol. 1, no. Economic Research Series, pp. 1-4, 2016.

[10] M. Cant and J. Wiid, "Establishing The Challenges Affecting South African SMEs.," Int. Bus. Econ. Res. J., vol. 12, no. 6, pp. 707-716, 2013.

[11] C. Kauffmann, "Financing SMEs in Africa," African Economic Outlook 2004/2005, no. 7, pp. 1-4, 2005.

[12] D. W. Yiu, J. Su, and Y. Xu, "Alternative Financing and Private Firm Performance," Asia Pacific J. Manag., vol. 30, no. 3, pp. 829-852, 2013.

[13] J. Y. Lin, "China and The Global Economy," China Econ. J., vol. 4, no. 1, pp. 1-14, 2011.

[14] J. Abor and P. Quartey, "Issues in SME Development in Ghana and South Africa," Int. Res. J. Financ. Econ., vol. 39, no. 39, pp. 218-228, 2010.

[15] K. S. Tsai, "Financing Small and Medium Enterprises in China: Recent Trends and Prospects beyond Shadow Banking," HKUST IEMS, vol. No 2015-24, no. HKUST IEMS Working Paper, p. 50, 2015.

[16] J. Hussain, C. Millman, and H. Matlay, "SME financing in the UK and in China: a comparative perspective," J. Small Bus. Enterp. Dev., vol. 13, no. 4, pp. 584-599, 2006.

[17] B. L. Rigouzzo, "Private Sector Development," no. 1, pp. 258-261, 2009.

[18] J. W. Berry, "Immigration, Acculturation, and Adaptation," Appl. Psychol., 1997.

[19] G. Csibra and G. Gergely, "Natural Pedagogy As Evolutionary Adaptation," Philosophical Transactions of the Royal Society B: Biological Sciences. 2011.

[20] M. Salahuddin and J. Gow, "The effects of Internet usage, financial development and trade openness on economic growth in South Africa: A time series analysis," Telemat. Informatics, 2016.

[21] P. Y. K. Chau, F. Lai, and D. Li, "What Factors Drive the Assimilation of Internet Technologies in China?," Commun. ACM, 2008.

[22] C. J. Frid, D. M. Wyman, W. B. Gartner, and D. H. Hechavarria, "Low-wealth entrepreneurs and access to external financing," Int. J. Entrep. Behav. Res., 2016.

[23] A. Conti, M. Thursby, and F. T. Rothaermel, "Show me the right stuff: Signals for high-tech startups," J. Econ. Manag. Strateg., 2013.

[24] A. Davila, G. Foster, and M. Gupta, "Venture capital financing and the growth of startup firms," J. Bus. Ventur., 2003.

[25] S. J. Chang, "Venture capital financing, strategic alliances, and the initial public offerings of 
Internet startups," J. Bus. Ventur., 2004.

[26] T. Kiisel, Getting a business loan: Financing your main street business. 2013. 